\title{
Piet Odendaal - A Life of Service to Clean Air (1936 - 2007)
}

\author{
Harold Annegarn and Flip Buys
}

Piet Odendaal, Director of NACA, passed away from a heart attack on Tuesday $18^{\text {th }}$ September 2007 , just days after returning from the 14th IUAPPA World Congress in Brisbane Australia.

Pieter Odendaal grew up and went to school in Standerton. Piet's early life was not one of privilege - he was one of four brothers, raised by his mother mainly as a single parent. He matriculated in 1954 with three distinctions, mathematics, science and accountancy. He started his work career as an assayer at a gold mine in Springs, and attended night classes a the Wits Technical College to complete his education. He obtained his BSc at the University of Pretoria graduating in Chemistry and Mathematics while working as a laboratory assistant to pay his way. While working at the Mint, he studied for and was capped with a BCom degree. Piet then joined the civil service as an officer in the Air Pollution Control Section of the Department of Health, which was later transferred to the Department of Environmental Affairs and Tourism. Pieter was promoted to Deputy Director Administration in the Air Pollution Control Section, a position he occupied until his retirement in 1996. In his retirement, Piet resumed his career of service to the cause of Clean Air when he as appointed in 2000 as Technical Director of the National Association for Clean Air.

These are the unadorned facts marking the milestones of the career of Pieter Odendaal. In conversations with his colleagues and friends he is described as friendly knowledgeable in his field, always ready to share information. To the industrialists with whom he interacted as a regulator, he was distinguished as invariably courteous, a skilful, non-confrontational negotiator. In his senior post in the Department Piet notched up several important policy and research achievements. He guided implementation of the Vehicle Emissions

Control research programme in the late 90's. He was instrumental in establishing one of the first public-private regulatory cooperatives in the form of APOLCOM (Air Pollution Committee) in Mpumalanga, well before the notion of Public Private Partnerships become fashionable. Through APOLCOM he was able to coax large emitting industries to clean air implementations far beyond the limited powers vested in the inspectorate through the Clean Air Act of 1965. Piet acted as administrative secretary for the National Air Pollution Advisory Committee, which provided direct guidance to the Minister. He provided loyal service to the Chief Air Pollution Control Officer, Mr Martin Lloyd, and headed a small but cohesive team of air pollution inspectors that dealt with the daunting task of supervising emissions controls in several hundred South African industries. This legendary team which oversaw implementation of the Air Pollution Prevention Act for over three decades included Pottie Potgieter, Julius van Graan, Jan Marais, Pieter du Toit, and Flip Buys.

In his second career as Technical Director of NACA,
Piet played a significant role in guiding NACA's deliberations on drafts of the Clean Air Act of 2004, leading to a measured, broadly consultative response to the proposed Act. Piet's leadership created an environment of rapprochement between the DEAT Directorate Air Quality and civil society professionals represented by the members of

NACA. Piet's non-confrontational style led to the best possible outcome, when members of NACA were appointed or engaged in various ways to assist with the drawing up of protocols, regulations etc. for implementation of the new Act. In his role of Technical Director of NACA, Piet was also the international face of air quality management of South Africa, representing NACA at the IUAPPA World Congress in Brisbane just days before his passing.

Piet was renowned for inventing a new South African tradition, the "beraai", a social occasion mixing the elements of a beraad and a braai. At these events, ostensibly social occasions with colleagues and friends, information and discussions of a more serious nature were exchanged, leading to greater understanding of the technical and legal challenges faced by the air pollution control office, and better cohesion among the small team of national air pollution inspectors. He also coined the phrase: Join air pollution and see the country (and the World)"

Underlying these career achievements was a man of deep principle and conviction. Piet was an Afrikaner, and proud of it. Yet the Christian values that governed his life guided his behaviour in all aspects of professional, social and private life. His camaraderie was not superficial bonhomie, but part of a deep held Christian ethic always to be positive and respectful in all interactions. He chose a career of public service, but never retreated behind officiousness. He did not bluster with the threat of power or prosecution invested in his office. He never gossiped. He held firm views, but never expressed them in a loud voice. As with many of us, he was caught up in the tumultuous political events of South Africa's transition to democracy. It is to the credit of his principled life that he was held in as high esteem after the transition as before, respected by all racial groups, by the private, the public and the NGO sectors. The metaphor of a ship tossed upon stormy seas is an enduring image in the Christian tradition of the vicissitudes of life. Piet was like the keel of a yacht, hidden below the water, but holding the vessel upright, mediating between the conflicting forces of wind and wave to give the ship purposeful direction. For those of us privileged to know and work with Piet, he provided the keel of our clean air activities. Always there, always a steadying, rational force, sustaining the direction and purpose of our collective endeavours.

We mourn the loss of our friend and colleague Piet Odendaal, and at the same time celebrate a well lived life, dedicated to providing one of the greatest gifts of for all of us to share, the gift of clean air. 